\title{
QTL fine-mapping of soybean (Glycine max L.) leaf type associated traits in two RILs populations
}

Liang Wang ${ }^{1,2,3}$, Yanbo Cheng ${ }^{1,2,3}$, Qibin Ma ${ }^{1,2,3}$, Yinghui Mu ${ }^{1,2,3}$, Zhifeng Huang ${ }^{1,2,3}$, Qiuju Xia ${ }^{4}$, Gengyun Zhang ${ }^{4}$ and Hai Nian ${ }^{1,2,3^{*}}$ (D)

\begin{abstract}
Background: The different leaf type associated traits of soybean (Glycine max L.) including leaf area, leaf length, leaf width, leaf shape and petiole length are considered to be associated with seed yield. In order to identify quantitative trait loci (QTLs) affecting leaf type traits, two advanced recombinant inbred line (RIL, ZH, Zhonghuang 24× Huaxia 3; GB, Guizao $1 \times$ Brazil 13) populations were introduced to score phenotypic values in plants across nine different environments (years, seasons, locations and soybean growth stages). Two restriction site-associated DNA sequencing (RAD-seq) based high-density genetic linkage maps with an average distance of 1.00 centimorgan (CM) between adjacent bin markers were utilized for QTL fine mapping.
\end{abstract}

Results: Correlation analysis showed that most of the traits were correlated with each other and regulated both by hereditary and environmental factors. A total of 190 QTLs were identified for leaf type associated traits in the two populations, of which 14 loci were found to be environmentally stable. Moreover, these detected QTLs were categorized into 34 QTL hotspots, and four important QTL hotspots with phenotypic variance ranging from 3.89-23.13\% were highlighted. Furthermore, Glyma04g05840, Glyma19g37820, Glyma14g07140 and Glyma19g39340 were predicted in the intervals of the stable loci and important QTL hotspots for leaf type traits by adopting Gene Ontology (GO) enrichment analysis.

Conclusions: Our findings of the QTLS and the putative genes will be beneficial to gain new insights into the genetic basis for soybean leaf type traits and may further accelerate the breeding process for reasonable leaf type soybean.

Keywords: Soybean, Leaf type traits, QTL, Fine mapping

\section{Background}

Soybean (Glycine max L.) is one of the major crops abundant in protein and oil contents, which can fix nitrogen via microorganisms in the soil as well as a model plant for legume research [1, 2]. Reasonable leaf type traits are essential for soybean yield improving. Heath and Gregory first emphasized the strong relationships between leaf area (LA)

\footnotetext{
* Correspondence: hnian@scau.edu.cn

'The State Key Laboratory for Conservation and Utilization of Subtropical Agro-bioresources South China Agricultural University, Guangzhou 510642, Guangdong, People's Republic of China

${ }^{2}$ The Key Laboratory of Plant Molecular Breeding of Guangdong Province, College of Agriculture, South China Agricultural University, Guangzhou

510642, Guangdong, People's Republic of China

Full list of author information is available at the end of the article
}

and yield [3]. Decades later, Board and Harville demonstrated that LAI values required at least 3.5-4.0 in early reproductive growth stages for the maximum yield in soybean [4]. Likewise, leaf length (LL), leaf width (LW) and leaf shape (LS) have also been widely focused by breeders for many years [5-9]. Noteworthily, petiole length (PL) also makes much sense to soybean yield. According to the study of Jun and Kang, a short petiole length phenotype was more favorable for altering plant leaf angles to a vertical inclination form and improving plant density to obtain a high seed yield [10]. Therefore, it is imperative to dissect the genetic basis of these leaf type traits in soybean breeding.

(c) The Author(s). 2019 Open Access This article is distributed under the terms of the Creative Commons Attribution 4.0 International License (http://creativecommons.org/licenses/by/4.0/), which permits unrestricted use, distribution, and 
With the development of next generation sequencing (NGS), discovering and genotyping for high-density single nucleotide polymorphisms (SNPs) data throughout the whole genome is now possible, which might useful to gain more information for marker-assisted selection (MAS) breeding process [11]. Genetic maps are effective tools for finding, dissecting and modifying the genes that determine simple and sophisticated traits in crops [12]. Restriction-site association DNA (RAD) technique together with the NGS is a cost-effective method that can simultaneously detect thousands of SNPs [13], and has been used for integrating high-density linkage maps and genetic analysis in plants, such as rice [14], sunflower [15], wheat [16], grape [17] and soybean [18-21]. Recently, genome-wide association study (GWAS) has become popular due to its high-resolution mapping when it was compared to conventional linkage mapping for dissecting complex genetic plant traits [22]. For instance, Li et al. genotyped 245 sorghum accessions by 85,585 SNPs and a total of 42 SNPs were identified to be associated with the five forage quality-related traits [23]. In another study, Phan et al. developed a core collection of 192 tomato accessions and evaluated for six fruit traits. As a result, they identified two loci for fruit color, seven loci for fruit shape, 11 loci for pericarp thickness, 13 loci for fruit weight, seven loci for fruit height, and ten loci for fruit width [24]. Fang et al. collected 809 soybean accessions worldwide and phenotyped them for 84 agronomic traits, 245 significant genetic loci for the target traits were discovered through GWAS [25].

A number of important bi-parental and GWAS QTLs for soybean agronomic traits have been reported over decades. To date, at least 40, 68, 66 and 87 QTLs controlling LA, LL, LW and LS have been detected, respectively (https://www.soybase.org/), based on various hereditary backgrounds, environments and statistical methods. Moreover, there is no QTL record for PL on SoybaseDatabase. In this study, we focused on LA, LL, LW, LS and PL across multiple environments by using two RIL populations as well as their RAD-seq based high-density genetic maps. The research aims of our study are as follows: (1) to map QTLs for leaf type associated traits in RIL populations and compare these data with previous research on SoybaseDatabase, (2) to determine if any QTLs were stable across multiple environments, (3) to select candidate genes in QTLs-based genetic intervals using Gene Ontology (GO) enrichment analysis.

\section{Results}

\section{Phenotypic analysis of RIL populations}

Phenotypic values for each RILs of two populations were performed across multiple environments. In most cases, leaf type traits of the male parent soybeans ('Huaxia 3' and 'Brazil 13') took higher values compared with those of female parents ('Zhonghuang 24' and 'Guizao 1'), providing ideal materials for map-based QTL analysis. Moreover, the phenotypic values floated with different environments. Overall, the RIL phenotypic values presented wide spans and displayed continuous distributions. The frequency distributions of individual phenotypic data for two RIL populations were depicted in Fig. 1. As is shown in the figure, the segregations of these traits fit skew normal or normal distribution models, with typical quantitative genetic characteristics. Furthermore, the skewness and kurtosis of the distributions were listed in Tables 1 and 2. Notably, there were transgressive segregations both found in two RILs suggesting the existence of positive-effected alleles in the parental soybeans.

The phenotypic value correlation analysis of the two RILs in each specific environment (Additional file 1: Tables S1 and S2) showed that most of the leaf type traits were highly correlated to each other and exhibited statistically significant $(P<0.01)$. Generally, LA and LW presented the highest positive correlation coefficients in the two populations. In this study, LA usually showed negative correlation to LS and the correlation coefficients in $\mathrm{ZH}$ population were universally weaker than those in GB population. Comparatively, LL and LW shared substantially positive correlation with each other. Moreover, LS was derived from the ratio LL to LW and exposed substantial positive correlation to LL and negative to LW in most cases. Interestingly, PL was highly associated with LA, LL and LW, but did not show significant relation to LS in the two populations. Furthermore, we analyzed the correlations between different environments for each target leaf type trait in two RILs. As is shown in Additional file 1: Tables S3 and S4, for the same planting location (Zengcheng), the correlation coefficients of various environments were broadly found to be significantly positive. In ZH RIL population, for all the five leaf type traits, the R4 (full pod reproductive) growth stage in the summer of 2017 at Zengcheng displayed the strongest correlations to other environments. Correspondingly, the most prominent environment in GB population was the R6 (full seed reproductive) growth stage in the summer of 2017 at Zengcheng. Particularly, for the different cultivating sites, the analysis data of GB RIL population at the R6 growth stage in the summer of 2017 at the Guangzhou experimental station presented widely weak relationship to those at Zengcheng.

Exploration of leaf type trait QTLs in two RIL populations With the SNP genotyping method, 47,472 and 56,561 high-quality polymorphic SNP sites were detected for $\mathrm{ZH}$ and GB RILs, respectively. All the SNP sites in the RILs were integrated as recombination bin units. 


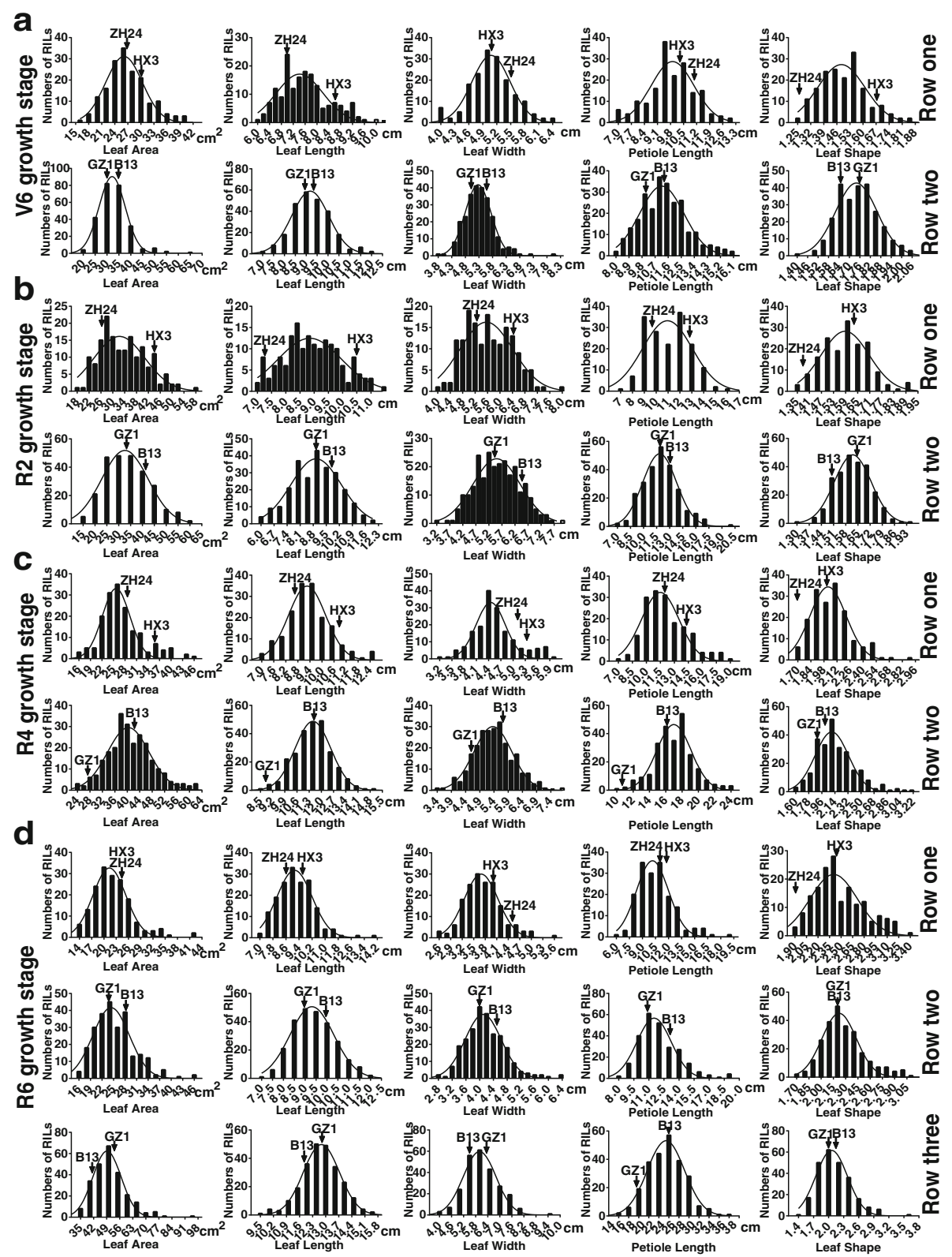

Fig. 1 Frequency distributions for leaf type associated traits in ZH and GB RILs. The arrows indicate traits related values for the two parents used to construct the RIL population (cv. Zhonghuang 24 and Huaxia 3; cV. Guizao 1 and Brazil 13). a The frequency distribution for leaf type associated traits at soybean V6 growth stage, the 'Row one' and 'Row two' are corresponding to ZH and GB RILs in the summer of 2017 at Zengcheng, respectively; b The frequency distribution for leaf type associated traits at soybean R2 growth stage, the 'Row one' and 'Row two' are corresponding to ZH and GB RILs in the spring of 2017 at Zengcheng, respectively; c The frequency distribution for leaf type associated traits at soybean R4 growth stage, the 'Row one' is corresponding to ZH RILs in the summer of 2017 at Zengcheng, the 'Row two' is corresponding to GB RILs in the spring of 2016 at Zengcheng; d the frequency distribution for leaf type associated traits at soybean R6 growth stage, the 'Row one' and 'Row two' are corresponding to ZH and GB RILs in the summer of 2017 at Zengcheng, respectively; the 'Row three' is corresponding to GB RILs in the summer of 2017 at the Guangzhou experimental station

As a result, 2639 recombinant bins were obtained for ZH RILs and 3715 bins for GB RILs (Additional file 1: Tables S5 and S6). Based on genotypes of these marker bins, two high-density bin linkage maps were constructed (Figs. 2 and 3), with an average distance of $1.00 \mathrm{cM}$ between adjacent markers [20]. By taking the composite interval mapping (CIM) method as well as utilizing the corresponding maps, 190 QTLs for leaf type traits have been discovered in the two RIL populations.

In ZH RIL population, 56 QTLs for the target five leaf traits were identified on 14 chromosomes $(02,03,04,06$, $08,09,10,11,12,13,14,15,17$ and 19) (Additional file 
Table 1 Leaf type traits in ZH RILs in different environments

\begin{tabular}{|c|c|c|c|c|c|c|c|c|c|}
\hline \multirow[t]{2}{*}{ Traits } & \multicolumn{2}{|c|}{ Parents Average } & \multicolumn{4}{|c|}{ RILs Lines Average } & \multirow[t]{2}{*}{ Skewness } & \multirow[t]{2}{*}{ Kurtosis } & \multirow{2}{*}{$\begin{array}{l}\text { Year, seasons, } \\
\text { location and } \\
\text { growth stages }\end{array}$} \\
\hline & $\overline{Z H} 24^{a, b}$ & $\mathrm{HX} 3^{\mathrm{a}, \mathrm{b}}$ & Minimum $^{\mathrm{a}, \mathrm{b}}$ & Maximum $^{\mathrm{a}, \mathrm{b}}$ & Mean $^{a, b}$ & $S D^{a, b}$ & & & \\
\hline $\mathrm{LA}^{a}$ & $26.85 \pm 3.43$ & $30.02 \pm 4.88$ & 16.86 & 40.96 & 26.85 & 4.77 & 0.49 & 0.09 & 2017Sum-Z-V6 \\
\hline$L L^{b}$ & $6.91 \pm 0.43$ & $8.57 \pm 0.78$ & 6.04 & 9.98 & 7.60 & 0.82 & 0.54 & -0.19 & \\
\hline LW $^{\mathrm{b}}$ & $5.50 \pm 0.36$ & $5.10 \pm 0.42$ & 3.91 & 6.36 & 5.09 & 0.47 & 0.04 & 0.23 & \\
\hline $\mathrm{PL}^{\mathrm{b}}$ & $11.12 \pm 1.89$ & $10.39 \pm 1.56$ & 6.80 & 12.97 & 9.84 & 1.24 & -0.14 & 0.01 & \\
\hline LS & $1.26 \pm 0.03$ & $1.68 \pm 0.06$ & 1.26 & 1.86 & 1.49 & 0.12 & 0.48 & 0.09 & \\
\hline$L A^{a}$ & $26.42 \pm 2.21$ & $44.18 \pm 3.65$ & 18.68 & 57.24 & 33.67 & 7.68 & 0.50 & -0.27 & 2017Spr-Z-R2 \\
\hline$L^{b}$ & $7.25 \pm 0.37$ & $10.46 \pm 0.51$ & 7.02 & 11.28 & 8.92 & 0.97 & 0.17 & -0.56 & \\
\hline $\mathrm{LW}^{\mathrm{b}}$ & $5.25 \pm 0.22$ & $6.43 \pm 0.26$ & 4.06 & 7.83 & 5.63 & 0.75 & 0.28 & -0.53 & \\
\hline $\mathrm{PL}^{\mathrm{b}}$ & $9.73 \pm 0.73$ & $12.79 \pm 0.82$ & 6.98 & 16.11 & 11.02 & 1.77 & 0.17 & -0.75 & \\
\hline LS & $1.38 \pm 0.04$ & $1.63 \pm 0.03$ & 1.36 & 1.92 & 1.59 & 0.11 & 0.35 & 0.15 & \\
\hline$L A^{a}$ & $28.51 \pm 3.14$ & $35.86 \pm 2.22$ & 15.20 & 45.52 & 27.05 & 5.48 & 0.92 & 1.21 & 2017Sum-Z-R4 \\
\hline $\mathrm{LL}^{\mathrm{b}}$ & $8.66 \pm 0.50$ & $10.85 \pm 0.21$ & 6.91 & 12.46 & 9.36 & 1.06 & 0.44 & 0.65 & \\
\hline $\mathrm{LW}^{\mathrm{b}}$ & $5.13 \pm 0.31$ & $5.31 \pm 0.29$ & 3.21 & 5.91 & 4.55 & 0.53 & 0.58 & 0.43 & \\
\hline $\mathrm{PL}^{\mathrm{b}}$ & $11.92 \pm 1.43$ & $14.35 \pm 1.92$ & 7.29 & 19.14 & 12.11 & 2.27 & 0.71 & 0.35 & \\
\hline LS & $1.69 \pm 0.06$ & $2.04 \pm 0.09$ & 1.67 & 2.93 & 2.07 & 0.21 & 0.92 & 1.28 & \\
\hline $\mathrm{LA}^{\mathrm{a}}$ & $24.44 \pm 3.96$ & $24.45 \pm 3.82$ & 13.50 & 42.99 & 22.23 & 4.91 & 1.23 & 2.83 & 2017Sum-Z-R6 \\
\hline$L^{b}$ & $8.61 \pm 0.75$ & $9.59 \pm 0.80$ & 7.04 & 13.84 & 9.21 & 1.11 & 0.70 & 1.50 & \\
\hline $\mathrm{LW}^{\mathrm{b}}$ & $4.52 \pm 0.46$ & $3.94 \pm 0.29$ & 2.61 & 5.58 & 3.74 & 0.49 & 0.56 & 1.05 & \\
\hline $\mathrm{PL}^{\mathrm{b}}$ & $10.96 \pm 1.84$ & $11.51 \pm 1.21$ & 6.41 & 18.94 & 10.56 & 2.14 & 0.93 & 1.27 & \\
\hline LS & $1.91 \pm 0.16$ & $2.43 \pm 0.13$ & 1.86 & 3.45 & 2.49 & 0.33 & 0.59 & -0.29 & \\
\hline
\end{tabular}

$L A$ leaf area, $L L$ leaf length, $L W$ leaf width, $P L$ petiole length, $L S$ leaf shape, $S D$ Standard deviation; ${ }^{\mathrm{a}} \mathrm{cm}^{2},{ }^{\mathrm{b}} \mathrm{cm}, 2017 \mathrm{Spr} 2017$ spring, 2017 Sum 2017 summer, $Z$ Zengcheng, V6 V6 growth stage, R2 R2 growth stage, R4 R4 growth stage, R6 R6 growth stage

1: Table S7). These QTLs were able to explain phenotypic variation ranging from $5.36 \%(q L A 14 b)$ to $18.23 \%$ ( $q L W 4 b)$ with the LOD values 2.51 to 7.86 . Among these QTLs, 11, 10, 12, 11 and 12 QTLs were mapped for LA, LL, LW, LS and PL, respectively. $q L A 4 b$ was detected by the bin19 marker on chromosome 4 in $\mathrm{ZH}$ population with phenotypic variance contribution up to $12.22 \%$ and was the most prominent QTL for LA. Moreover, $q L A 4 b$ displayed a negative additive effect which indicated the positive functions of the alleles derived from 'Huaxia 3'. Coincidentally, $q L W 4 b$ was also identified by the bin 19 marker which shared the physical interval $3,657,048$ to $3,740,933$ bp with $q L A 4 b$ in the same environment and was the most dominant effect QTL for LW as well. Comparatively, $q L W 4 b$ showed a greater phenotypic variance $\left(R^{2}=18.23 \%\right)$ and positive additive effect. Furthermore, we designated $q L L 3 b$, qLS6a-2 and qPL19d as the leading QTLs for LL, LS and PL due to their relatively advanced genetic effects $\left(R^{2}=10.54,10.92\right.$ and $\left.15.70 \%\right)$.

Accordingly, there were 134 detected QTLs almost fully covered the whole genome (except for chromosome 15) through five circumstances in GB RIL population (Additional file 1: Table S8). Noticeably, a wider range phenotypic variance spanned from $2.71 \%$ (qLS3i) to 23.13\% ( $q L W 4 f-1$ ) and LOD score distributions from 2.56 to 16.15 were also demonstrated. An entire of 24, 26, 24, 34 and 26 QTLs were identified for LA, LL, LW, LS and PL in GB population. In addition, $q L A 4 f-1, q L L 4 f-1$, $q L W 4 f-1$ and $q P L 7 g$ were four major QTLs with the leading phenotypic variance contributions $\left(R^{2}=22.83,22.53\right.$, 23.13 and $10.22 \%$ ) in their respective traits. Moreover, all of them showed negative additive effects, which revealed the acquisition of favorable alleles from Brazil 13. Furthermore, $q L S 19 g-1, q L S 19 h$ and $q L S 19 i-1$ presented positive additive effects across three different environments and were three major QTLs $\left(R^{2} \geq 10 \%\right)$ for LS in GB population.

\section{Identification of stable loci and important QTL hotspots for leaf type traits}

The entirely detected QTLs in ZH and GB RIL populations were then subdivided into 48 and 100 loci based on the overlapped bins (Additional file 1: Tables S7 and S8). The loci name was composited with the first letter of the RIL population name (known as ' $Z$ ' or ' $G$ ') and 'loci', then consecutively numbered with Arabic numerals. In the present study, there were 14 stable loci 
Table 2 Leaf traits in GB RILs in different environments

\begin{tabular}{|c|c|c|c|c|c|c|c|c|c|}
\hline Traits & Parents & & RILs Lines & & & & Skewness & Kurtosis & $\begin{array}{l}\text { Years, seasons, locations } \\
\text { and growth stages }\end{array}$ \\
\hline & $\mathrm{GZ} 1^{\mathrm{a}, \mathrm{b}}$ & $\mathrm{B} 13^{\mathrm{a}, \mathrm{b}}$ & Minimum $^{a, b}$ & Maximum ${ }^{a, b}$ & Mean $^{a, b}$ & $S D^{a, b}$ & & & \\
\hline$L A^{a}$ & $30.42 \pm 4.74$ & $34.72 \pm 2.67$ & 18.26 & 64.20 & 32.84 & 6.18 & 1.12 & 3.42 & 2017Sum-Z-V6 \\
\hline $\mathrm{LL}^{\mathrm{b}}$ & $8.87 \pm 0.80$ & $9.26 \pm 0.45$ & 6.93 & 12.00 & 9.26 & 0.90 & 0.36 & 0.39 & \\
\hline LW $^{b}$ & $5.03 \pm 0.39$ & $5.60 \pm 0.22$ & 3.85 & 8.17 & 5.31 & 0.55 & 0.86 & 3.00 & \\
\hline $\mathrm{PL}^{\mathrm{b}}$ & $10.16 \pm 1.20$ & $11.38 \pm 0.74$ & 8.07 & 16.19 & 11.35 & 1.60 & 0.50 & 0.19 & \\
\hline LS & $1.76 \pm 0.03$ & $1.65 \pm 0.06$ & 1.41 & 2.07 & 1.75 & 0.11 & 0.19 & -0.21 & \\
\hline$L A^{a}$ & $32.85 \pm 1.02$ & $41.57 \pm 2.09$ & 13.51 & 59.74 & 33.73 & 9.25 & 0.35 & -0.34 & 2017Spr-Z-R2 \\
\hline $\mathrm{LL}^{\mathrm{b}}$ & $8.91 \pm 0.18$ & $9.74 \pm 0.32$ & 6.10 & 11.88 & 8.93 & 1.26 & -0.07 & -0.49 & \\
\hline $\mathrm{LW}^{\mathrm{b}}$ & $5.43 \pm 0.10$ & $6.44 \pm 0.11$ & 3.29 & 7.76 & 5.52 & 0.85 & 0.14 & -0.43 & \\
\hline$P L^{b}$ & $11.80 \pm 1.03$ & $13.01 \pm 0.51$ & 6.66 & 20.06 & 11.98 & 2.04 & 0.34 & 0.60 & \\
\hline LS & $1.64 \pm 0.04$ & $1.51 \pm 0.03$ & 1.31 & 1.94 & 1.62 & 0.10 & 0.06 & -0.03 & \\
\hline$L A^{a}$ & $27.41 \pm 4.69$ & $42.64 \pm 6.84$ & 23.16 & 62.92 & 41.13 & 7.32 & 0.38 & 0.38 & 2016Sum-Z-R4 \\
\hline $\mathrm{LL}^{\mathrm{b}}$ & $8.79 \pm 0.94$ & $11.55 \pm 0.58$ & 8.49 & 15.06 & 11.52 & 1.06 & 0.08 & 0.20 & \\
\hline $\mathrm{LW}^{\mathrm{b}}$ & $4.60 \pm 0.49$ & $5.72 \pm 0.71$ & 3.34 & 7.66 & 5.40 & 0.70 & 0.17 & 0.16 & \\
\hline $\mathrm{PL}^{\mathrm{b}}$ & $10.74 \pm 1.43$ & $16.18 \pm 1.39$ & 9.72 & 23.75 & 17.01 & 2.40 & 0.09 & 0.49 & \\
\hline LS & $1.91 \pm 0.20$ & $2.02 \pm 0.23$ & 1.56 & 3.19 & 2.16 & 0.27 & 0.87 & 1.24 & \\
\hline$L A^{a}$ & $23.54 \pm 3.44$ & $28.23 \pm 4.53$ & 15.86 & 46.38 & 25.30 & 5.24 & 0.90 & 1.39 & 2017Sum-Z-R6 \\
\hline$L^{b}$ & $8.90 \pm 0.73$ & $9.90 \pm 0.87$ & 7.04 & 12.09 & 9.39 & 0.96 & 0.30 & -0.32 & \\
\hline $\mathrm{LW}^{\mathrm{b}}$ & $4.04 \pm 0.36$ & $4.49 \pm 0.42$ & 2.78 & 6.28 & 4.17 & 0.58 & 0.69 & 1.02 & \\
\hline $\mathrm{PL}^{\mathrm{b}}$ & $10.74 \pm 0.91$ & $13.13 \pm 2.02$ & 7.97 & 19.47 & 12.07 & 2.02 & 1.02 & 1.43 & \\
\hline LS & $2.20 \pm 0.16$ & $2.21 \pm 0.16$ & 1.73 & 3.11 & 2.28 & 0.26 & 0.76 & 0.58 & \\
\hline$L A^{a}$ & $52.57 \pm 5.63$ & $41.90 \pm 2.54$ & 32.63 & 94.89 & 50.95 & 8.94 & 0.99 & 2.15 & 2017Sum-G-R6 \\
\hline $\mathrm{LL}^{\mathrm{b}}$ & $12.80 \pm 0.08$ & $11.87 \pm 0.53$ & 9.67 & 15.61 & 12.76 & 1.05 & -0.12 & 0.26 & \\
\hline LW $^{b}$ & $6.33 \pm 0.47$ & $5.53 \pm 0.25$ & 3.92 & 9.67 & 6.11 & 0.86 & 0.40 & 0.49 & \\
\hline $\mathrm{PL}^{\mathrm{b}}$ & $17.48 \pm 2.74$ & $23.92 \pm 3.49$ & 13.80 & 35.91 & 23.52 & 3.67 & 0.15 & 0.25 & \\
\hline LS & $2.02 \pm 0.14$ & $2.15 \pm 0.09$ & 1.47 & 3.59 & 2.12 & 0.34 & 0.89 & 1.16 & \\
\hline
\end{tabular}

$L A$ leaf area, $L L$ leaf length, $L W$ leaf width, $P L$ petiole length, $L S$ leaf shape, SD Standard deviation; ${ }^{\mathrm{a}} \mathrm{cm}^{2},{ }^{\mathrm{b}} \mathrm{cm} 2016 \mathrm{Sum} 2016 \mathrm{summer}, 2017 \mathrm{Spr} 2017 \mathrm{spring}, 2017 \mathrm{Sum}$ 2017summer, Z Zengcheng, G Guangzhou, V6 V6 growth stage, R2 R2 growth stage, R4 R4 growth stage, R6 R6 growth stage

identified across multiple environments. In ZH RIL population, three loci (Z-loci-31, Z-loci-36 and $Z$-loci-37) for three leaf type traits (LL, LA and LW) were mapped onto two soybean chromosomes (11 and 14). Interestingly, all of them showed negative additive effects. Correspondingly, there were 11 loci distributed on seven chromosomes $(03,04,12,13,14,16$ and 19) in GB RILs, responding to all the five target leaf traits. Among them, six loci (G-loci-10, G-loci-15, G-loci-59, G-loci-63, G-loci-77 and G-loci-94) were found to be positive additive effects and five (G-loci-18, G-loci-23, G-loci-56, G-loci-65 and G-loci-93) presented negative effects. The details of them were listed in Table 3. Meanwhile, nearly all of them (except for G-loci-93) solely paralleled to one leaf type trait that may shed light on the genetic basis of specific leaf type trait construction.

Referring to Liu et al. determining criterion on QTL hotspots (so-called QTL clusters), the adjacent identified QTLs were categorized into 11 and 23 QTL hotspots for leaf type traits in ZH and GB RIL populations with a wide covering range on soybean genome [20]. Moreover, these QTL hotspots contained at least two QTLs and were named after 'LT' which represented the regulation of diverse leaf type traits. As is shown in Additional file 1: Table S9, the QTL hotspots of ZH RILs distributed on eight chromosomes (02, 03, 04, 06, 09, 11, 14 and 19). Compared to ZH RILs, the QTL hotspots of GB RILs spanned 13 chromosomes except for chromosomes 01, 05, 06, 07, 08, 10 and 15 (Additional file 1: Table S10). Intriguingly, most of the QTL hotspots with relatively high phenotypic variance contributions were converged into the genetic intervals on the front part of chromosome 04 and the posterior part of chromosome 19. Furthermore, four important stable QTL hotspots (qLT4Z-1, qLT19Z-2, qLT4G-2 and qLT19G-2) were evenly located on chromosomes 04 and 19 for $\mathrm{ZH}$ and GB RIL populations across multiple environments 


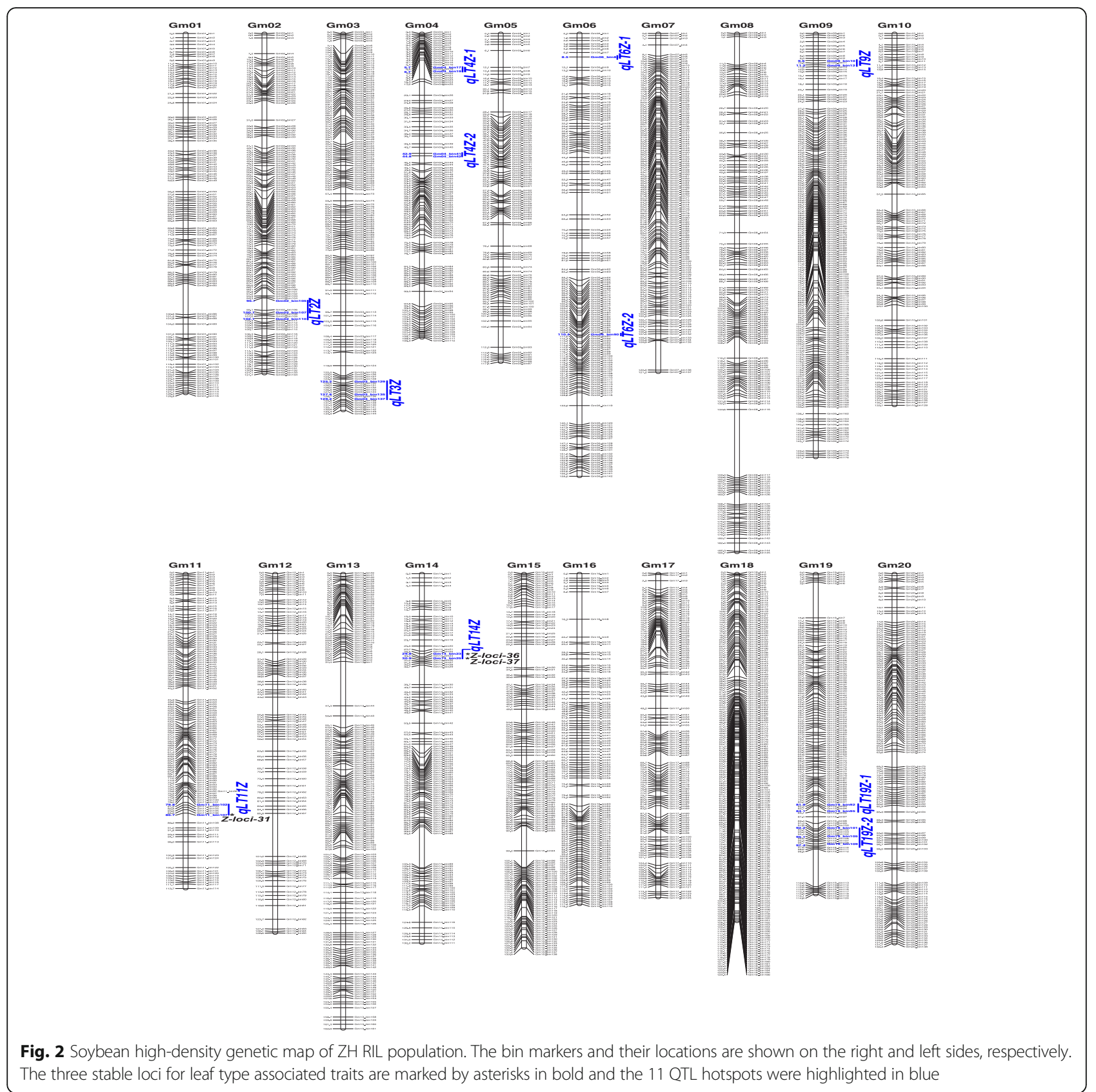

(Fig. 4). In ZH population, $q L T 4 Z-1$ was identified in an interval between $3,473,033$ and $3,740,933 \mathrm{bp}$ on chromosome 04 including three novel QTLs for three leaf type traits (LL, LA and LW) with the phenotypic variance up to $18.23 \%(q L W 4 b)$. Furthermore, $q L T 19 Z-2$ was located in a genetic block $44,764,317$ to $45,888,005$ bp on chromosome 19 with the phenotypic contribution ascending to $15.7 \%$ $(q P L 19 d)$ and is related to three QTLs for LW, PL and LS. In GB population, qLT4G-2 was an entry new QTL hotspot across multiple environments, responding to the five target leaf traits and the highest phenotypic variance was $23.3 \%(q L W 4 f-1)$. Likewise, $q L T 19$ G-2 with ten QTLs was able to explain the phenotypic variance ranging from $3.89 \%$ (qLA19i) to $20.53 \%(q L S 19 i-1)$ for LA, LW, PL and LS. Summarily, the four important QTL hotspots may play key role in regulating complicated traits in soybean leaves. Additionally, all of these stable loci and QTL hotspots have been marked on their accordant chromosomes in the constructed high-density genetic maps (Figs. 2 and 3). 


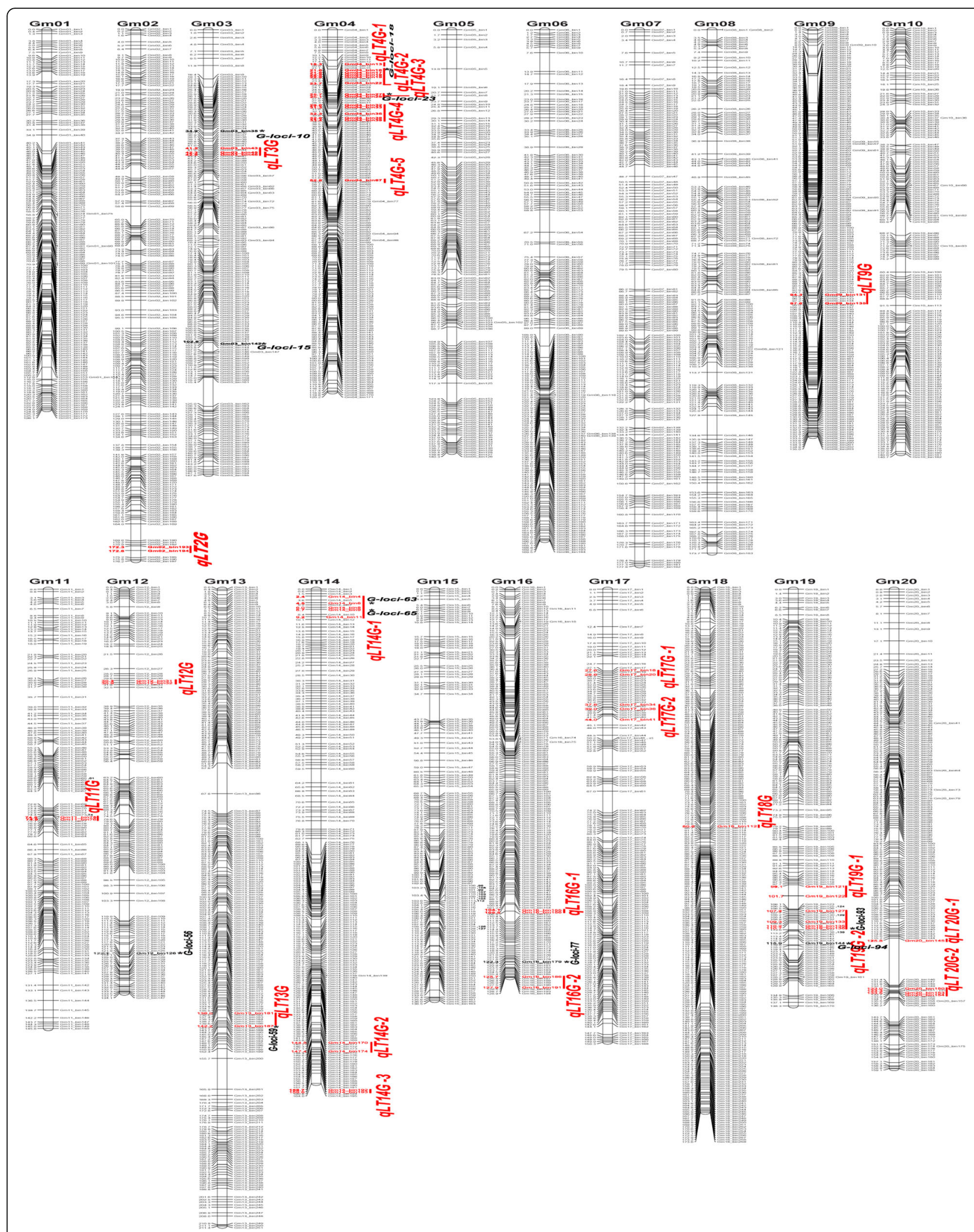

Fig. 3 Soybean high-density genetic map of GB RIL population. The bin markers and their locations are shown on the right and left sides, respectively. The 11 stable loci for leaf type associated traits are marked by asterisks in bold and the 23 QTL hotspots were highlighted in red 
Table 3 The 14 stable loci for leaf type traits in two populations across different environments

\begin{tabular}{|c|c|c|c|c|c|c|c|c|c|c|}
\hline RILs name ${ }^{a}$ & Loci name $^{\text {b }}$ & QTL name $^{c}$ & $\mathrm{Chr}^{\mathrm{d}}$ & Bin name & $\mathrm{Cl}_{\mathrm{v} 1.1}(\mathrm{bp})^{\mathrm{e}}$ & Position (cM) & $\operatorname{LOD}^{f}$ & $\mathrm{ADD}^{\mathrm{g}}$ & $R^{2}(\%)^{h}$ & $\mathrm{Cl}_{\mathrm{v} 2.0}(\mathrm{bp})^{\mathrm{i}}$ \\
\hline \multirow[t]{6}{*}{$\mathrm{ZH}$} & Z-loci-31 & qLL11C-2 & 11 & Bin107 & $36,478,191-36,619,869$ & 85.70 & 2.89 & -0.33 & 7.10 & $32,011,930-32,147,322$ \\
\hline & & qLL11d & 11 & Bin107 & $36,478,191-36,619,869$ & 85.70 & 2.99 & -0.30 & 6.77 & $32,011,930-32,147,322$ \\
\hline & Z-loci-36 & $q L A 14 a$ & 14 & Bin23 & $4,871,116-4,920,206$ & 29.80 & 2.71 & -1.18 & 6.06 & $4,954,181-5,005,224$ \\
\hline & & qLA14C & 14 & $\operatorname{Bin} 23$ & $4,871,116-4,920,206$ & 29.80 & 2.64 & -1.48 & 6.42 & $4,954,181-5,005,224$ \\
\hline & Z-loci-37 & $a L W 14 a$ & 14 & $\operatorname{Bin} 25$ & $5,292,323-5,333,084$ & 30.90 & 4.40 & -0.15 & 10.44 & $5,403,689-5,448,621$ \\
\hline & & $q L W 14 c-1$ & 14 & $\operatorname{Bin} 25$ & $5,292,323-5,333,084$ & 30.90 & 4.52 & -0.19 & 10.86 & $5,403,689-5,448,621$ \\
\hline \multirow[t]{27}{*}{ GB } & G-loci-10 & $q P L 3 g-1$ & 3 & Bin35 & $4,763,728-5,164,283$ & 34.90 & 3.65 & 0.56 & 5.19 & $4,566,741-5,065,688$ \\
\hline & & $q P L 3 i-2$ & 3 & Bin35 & $4,763,728-5,164,283$ & 34.90 & 2.87 & 0.75 & 4.28 & $4,566,741-5,065,688$ \\
\hline & G-loci-15 & qLS3h & 3 & Bin142 & $41,133,188-41,201,407$ & 102.80 & 3.30 & 0.05 & 3.61 & $39,126,123-39,181,924$ \\
\hline & & $q L S 3 i$ & 3 & Bin 142 & $41,133,188-41,201,407$ & 102.80 & 2.56 & 0.06 & 2.71 & $39,126,123-39,181,924$ \\
\hline & G-loci-18 & $q L L 4 e-1$ & 4 & Bin16 & $4,020,745-4,048,162$ & 21.60 & 5.11 & -0.26 & 7.51 & 4,070,205-4,094,078 \\
\hline & & $q L L 4 g-1$ & 4 & Bin16 & $4,020,745-4,048,162$ & 21.60 & 13.82 & -0.47 & 18.12 & $4,070,205-4,094,078$ \\
\hline & & $q L L 4 i$ & 4 & Bin16 & $4,020,745-4,048,162$ & 21.60 & 11.13 & -0.44 & 15.84 & $4,070,205-4,094,078$ \\
\hline & G-loci-23 & $q P L 4 f$ & 4 & $\operatorname{Bin} 27$ & $4,764,737-4,814,980$ & 25.70 & 2.77 & -0.42 & 4.01 & $4,822,857-4,873,263$ \\
\hline & & $q P L 4 g$ & 4 & $\operatorname{Bin} 27$ & $4,764,737-4,814,980$ & 25.70 & 4.63 & -0.63 & 6.47 & $4,822,857-4,873,263$ \\
\hline & G-loci-56 & $q L S 12 g$ & 12 & Bin 126 & $36,772,134-36,809,388$ & 122.10 & 2.63 & -0.05 & 3.00 & $36,730,431-36,766,381$ \\
\hline & & $q L S 12 h$ & 12 & Bin126 & $36,772,134-36,809,388$ & 122.10 & 3.48 & -0.05 & 4.06 & $36,730,431-36,766,381$ \\
\hline & G-loci-59 & qLW13g & 13 & Bin187 & $33,303,067-33,385,748$ & 142.20 & 2.60 & 0.13 & 3.32 & $34,514,243-34,601,384$ \\
\hline & & qLW13h & 13 & Bin187 & $33,303,067-33,385,748$ & 142.20 & 2.84 & 0.11 & 3.47 & $34,514,243-34,601,384$ \\
\hline & G-loci-63 & qLS14e & 14 & Bin6 & $495,526-538,526$ & 4.50 & 11.01 & 0.04 & 13.67 & $506,220-544,002$ \\
\hline & & $q L S 14 f$ & 14 & Bin6 & $495,526-538,526$ & 4.50 & 2.89 & 0.02 & 3.95 & $506,220-544,002$ \\
\hline & & $q L S 14 h$ & 14 & Bin6 & $495,526-538,526$ & 4.50 & 2.78 & 0.05 & 3.06 & $506,220-544,002$ \\
\hline & G-loci-65 & qLW14h & 14 & Bin9 & $664,663-746,688$ & 6.70 & 4.73 & -0.09 & 7.08 & 659,428-753,278 \\
\hline & & $q L W 14 i-1$ & 14 & Bin9 & $664,663-746,688$ & 6.70 & 3.85 & -0.20 & 4.91 & 659,428-753,278 \\
\hline & G-loci-77 & qLS16e & 16 & Bin179 & $35,798,290-35,892,430$ & 122.30 & 12.01 & 0.05 & 15.30 & $36,302,667-36,395,478$ \\
\hline & & $q L S 16 i$ & 16 & Bin179 & $35,798,290-35,892,430$ & 122.30 & 2.67 & 0.06 & 2.83 & $36,302,667-36,395,478$ \\
\hline & G-loci-93 & qLA19g & 19 & Bin136 & $45,183,988-45,457,039$ & 110.70 & 3.16 & -1.52 & 4.24 & $45,304,487-45,567,452$ \\
\hline & & qLA19h-2 & 19 & Bin136 & $45,183,988-45,457,039$ & 110.70 & 4.69 & -1.37 & 6.67 & $45,304,487-45,567,452$ \\
\hline & & qLA19i & 19 & Bin136 & $45,183,988-45,457,039$ & 110.70 & 2.65 & -1.79 & 3.89 & $45,304,487-45,567,452$ \\
\hline & & $q L W 19 g$ & 19 & Bin136 & $45,183,988-45,457,039$ & 110.70 & 12.83 & -0.30 & 18.31 & $45,304,487-45,567,452$ \\
\hline & & qLW19h-2 & 19 & Bin136 & $45,183,988-45,457,039$ & 110.70 & 9.64 & -0.21 & 12.76 & $45,304,487-45,567,452$ \\
\hline & G-loci-94 & $q L S 19 g-2$ & 19 & Bin144 & $46,060,014-46,274,131$ & 115.90 & 9.44 & 0.10 & 13.77 & $46,167,548-46,388,153$ \\
\hline & & qLS19i-2 & 19 & Bin144 & $46,060,014-46,274,131$ & 115.90 & 8.19 & 0.11 & 11.03 & $46,167,548-46,388,153$ \\
\hline
\end{tabular}

${ }^{\mathrm{a}} \mathrm{RIL}$ name: ZH Zhonghuang $24 \times$ Huaxia 3 RIL population; GB Guizao $1 \times$ Brazil 13 RIL population

${ }^{b}$ Loci name is composited with the first letter of RIL population name known as 'Z' or ' $G$ ' and 'loci' following its former order

'The name of QTL is a composite of the leaf traits: leaf area (LA); leaf length (LL); leaf width (LW); petiole length (PL); leaf shape (LS); a: the V6 growth stage in the summer of 2017 at Zengcheng; c: the R4 growth stage in the summer of 2017 at Zengcheng;d: the R6 growth stage in the summer of 2017 at Zengcheng; e: the V6 growth stage in the summer of 2017 at Zengcheng; f: the R2 growth stage in the spring of 2017 at Zengcheng; g: the R4 growth stage in the summer of 2016 at Zengcheng; h: the R6 growth stage in the summer of 2017 at Zengcheng; i: the R6 growth stage in the summer of 2017 at the Guangzhou experimental station ${ }^{\mathrm{d}} \mathrm{Chr}$ refers to chromosome

${ }^{\mathrm{e}}$ The physical position corresponding to the $95 \%$ confidence interval for the detected QTL based on Glyma.Wm82. a1. v1.1 gene model

fLOD indicates the logarithm of odds score

${ }^{9}$ Positive and negative values indicated additive effect by the alleles of parents, respectively

${ }^{\mathrm{h}} \mathrm{R}^{2}$ indicates the phenotypic variance explained by individual QTL

'The most proximal Glyma.Wm82.a2.v1 gene model physical intervals of the detected QTLs were transformed by focusing on the positions of the interval nearest 3 ' and 5 ' ending genes 
a

Gm04

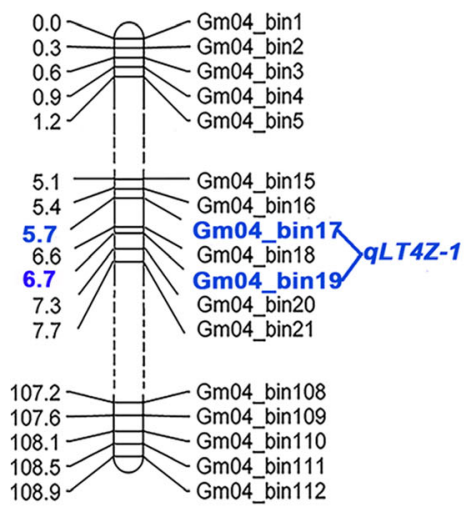

b
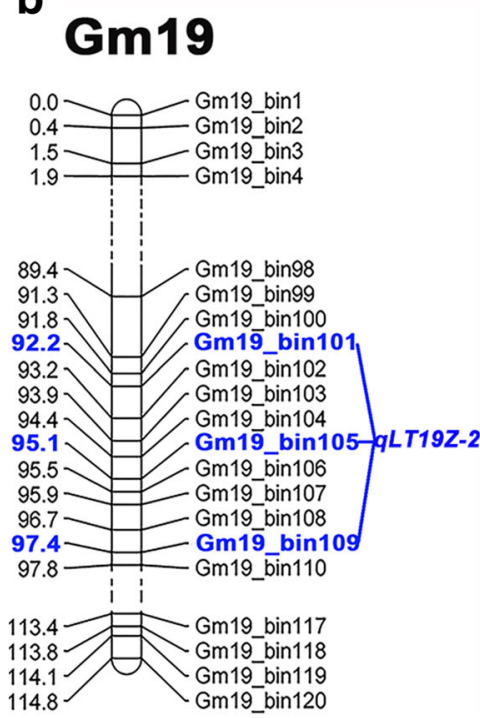

\section{Gm04}

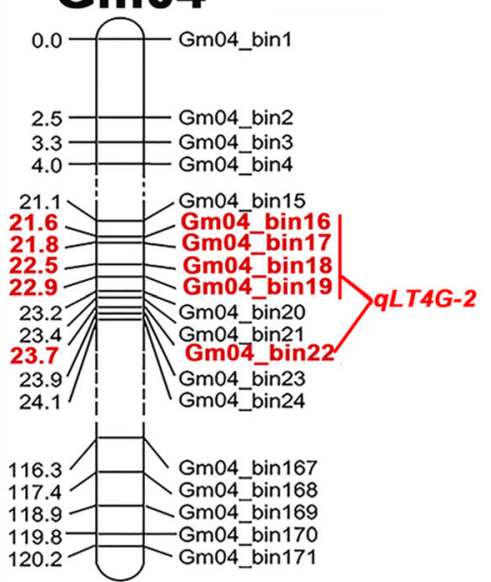

Gm19

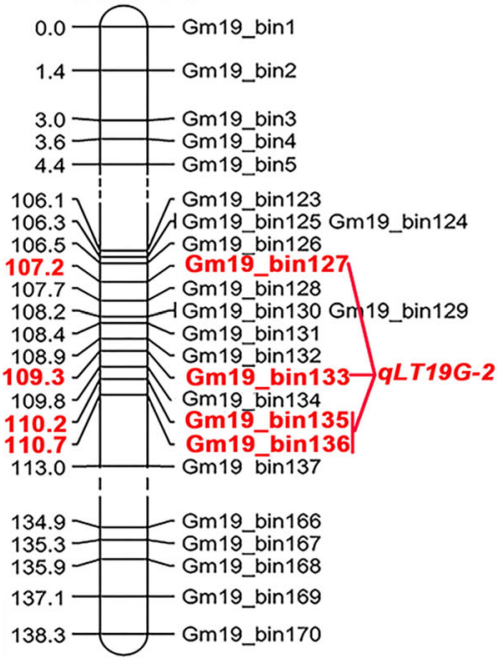

Fig. 4 Important QTL hotspots of leaf type traits in ZH and GB RIL population. The virtual point lines represent the truncated segments of chromosomes. The QTL hotspot names are composites of leaf type traits (LT) followed by the chromosome number. The corresponding bin markers have been emphasized in bold. The QTL hotspots in ZH and GB RIL populations were colored in blue and red, respectively. a the two important QTL hotspots on chromosome 04; $\mathbf{b}$ the two important QTL hotspots on chromosome 19

\section{Gene ontology (GO) enrichment analysis and candidate} gene prediction

In order to gain an in-depth understanding of which genes may relate to the integrated leaf type traits, we retrieved the gene calls in the genetic blocks of four important QTL hotspots. A total of 60 and 98 annotated genes were discovered in the genetic intervals of hotspots on chromosome 04 and chromosome 19, respectively (Additional file 1: Table S11). Among the 158 annotated genes, 81 were found to have at least one GO annotation. Furthermore, these genes were predicted to be related to various biological processes and could be grouped into 13 categories, including regulation of biological process, biological regulation, cellular process, metabolic process, establishment of localization, localization, transcription regulator activity, catalytic activity, binding, macromolecular complex, cell, cell part and organelle (Additional file 1: Table S12). Some biological processes such as metabolic processes, catalytic activity, and particularly transcription regulator activities are essential for gene expressions and metabolites in all organisms. Likewise, to further exploring the candidate genes of a certain specific leaf type trait, we focused on the 14 stable loci and carried out the analyzing procedures consistent with those on QTL hotspots. Subsequently, entire 206 gene calls were listed on (Additional file 1: Table S13) and $\mathrm{GO}$ analysis of the specific leaf type traits were summarized on (Additional file 1: Table S14).

By applying the GO enrichment analysis as well as considering the hereditary variation of mapping regions and 
the gene annotations on Phytozome (https://phytozome.jgi. doe.gov/pz/portal.html), we predicted four candidate genes. Among them, Glyma04g05840 and Glyma19g37820 were originated from the intervals of two important QTL hotspots (qLT4G-2 and qLT19Z-2). Comparably, Glyma14g07140 was found in the genetic region of a major stable loci (Z-loci-37) for LW in ZH RIL population, Glyma19g39340 was originated from the hereditary interval of a major stable loci (G-loci-94) for LS in GB RIL population.

\section{Discussion}

\section{Main effective factors for phenotype}

Xavier et al. previously reported that complex traits in soybean are regulated and controlled by multi-genetic as well as environmental factors [26]. As is shown in Tables 1 and 2, the leaf type associated traits phenotypic data of $\mathrm{ZH}$ and GB RIL populations at Zengcheng floated with different growth stages. Moreover, for the specific target trait, the phenotypic data exhibited obvious differences in two RIL populations. Hence, we extrapolated that the leaf type traits may influenced both by the related gene time expressions and different hereditary backgrounds [27]. According to the correlation analysis in Additional file 1: Tables S1-S4, most of the leaf type traits highly interacted with each other and this may support that functional gene may be pleiotropic or closely linked to some extent [28]. Noticeably, due to the different planting sites, the phenotype data of the R6 growth stage in the summer of 2017 at the Guangzhou experimental station for GB RILs almost showed no strong correlation to those at Zengcheng. From this aspect, the leaf type traits may affect by the environmental factors in GB RILs. Generally, the results of present study showed relatively good consistency with the former research.

\section{Influencing factors for QTL mapping}

Promoting genetic improvements of soybean by molecular approaches, which is one of the primary goals throughout soybean breeding [29]. The efficacy of QTL mapping is to acquire favorable alleles and seeking for genetic mechanisms. Many factors such as, parental hereditary diversity, environmental effects and molecular marker density may influence the precisions of QTL mapping [30]. The research aim of our study was to identify QTLs for five important leaf type traits in soybean. Previous studies have mapped different QTLs for these leaf type traits. Nevertheless, our study was distinct to the former researches in several important aspects. These included the application of two stably advanced RIL populations, which exceeded $F_{12}$ generations as well as relatively abounding segregation lines (164 ZH RILs and 256 GB RILs). Furthermore, we utilized two RAD-seq based high-density genetic linkage maps, making the QTL mapping more accurate and reliable. Meanwhile, for the parental genetic variation term, the parent soybeans had at least two distinctly different leaf type traits in any circumstance (Tables 1 and 2). Comparatively, 'Guizao 1' and 'Brazil 13' had obvious differences in LA, LW and PL across most environments, and 'Zhonghuang 24' and 'Huaxia 3' were more significantly diversified in LL and LS. In addition, by adopting a scanning method, we improved the accuracy as well as the efficiency of phenotypic data collections. Notably, we aggregately analyzed the leaf traits in various environments throughout different seasons and growth stages. In brief, we attempted to find some constantly stable QTLs and provided the orientation for shifting leaf type traits as well as improving soybean breeding process.

\section{Comparisons of the detected QTLs in the current study and the previous research}

Previously published QTLs for leaf type traits (LA, LL, LW and LS) widely distributed in the whole soybean genome [9, 25, 31-41] (Additional file 1: Table S15). In the present study, we compared and judged the relations between the detected leaf type QTLs in this study and the reported ones [9, 25, 31-35, 37-40] (Additional file 1: Tables S16 and S17). According to Additional file 1: Tables S16 and S17, the leaf type QTLs identified on chromosome 04 and chromosome 19 showed good inter-relevance between $\mathrm{ZH}$ and GB mapping populations. Notably, compared to the formerly published leaf type QTLs, most QTLs detected herein were novel ones. In addition, the detected QTLs in two populations on chromosome 19 also presented relatively strong correlations to the previously published leaf type QTLs. In comparison, on chromosome 04, the discovered genetic regions of the QTLs in current study have not been reported for QTL of leaf type trait before.

Interestingly, most of the detected QTLs which took considerable phenotypic variations in $\mathrm{ZH}$ and GB RIL populations were clustered into the hereditary regions on the front part of chromosome 04 and the posterior part of chromosome 19 (Additional file 1: Tables S7 and S8). In this study, we emphasized four important QTL hotspots in these regions. Many yield-related traits, like branching, pod number, seed weight, plant height, node number, seed set (so-called seed per pod) can affect soybean yielding [42-62]. qLT19Z-2 and $q L T 19$ G-2 are two important QTL hotspots correlated to leaf type traits identified in the genetic intervals on the posterior part of chromosome 19. As is shown in (Additional file 1: Table S18), a number of previously published QTLs for leaf type and yield-related traits clustered in the hereditary blocks of $q L T 19 Z-2$ and qLT19G-2 [25, 31, 34, 35, 38, 48-62]. Comparably, qLT4Z-1 and qLT4G-2 were novel QTL hotspots on chromosome 04 for leaf type traits in the current study. No early reported leaf trait QTL was identified in the genetic regions of the novel QTL hotspots. However, five and 
ten published yield-related QTLs were found in the hereditary blocks of $q L T 4 Z-1$ and $q L T 4 G-2$, respectively [4247]. In current study, the four important QTL hotspots contain 28 leaf type traits QTLs. The results in Additional file 1: Table S18 also demonstrated the correlations between the 28 leaf type QTLs and reported yield- related QTLs. Moreover, compared to former research, we fine mapped the QTLs for the petiole trait. Importantly, four detected QTLs for PL (qPL19d, qPL4h-1, qPL4e-1 and $q P L 19 h)$ were included by the four major leaf type QTL hotspots and corelated well with the previously reported and the present discovered QTLs. The coincidence of the QTLs across different genetic backgrounds and studies not only reveal the stability and reliability of the QTLs detected herein, but also highlight the significance of these regions in breeding to develop reasonable leaf type as well as high-yielding soybean cultivars.

\section{Four putative genes for soybean leaf type traits}

Plant leaf and petiole developed from a group of cells named the leaf primordium, which initiated at the brink of the shoot apical meristem (SAM) [63, 64]. Subsequently, cell division, differentiation and expansion are temporally and spatially coordinated to convert the infant leaf into a mature leaf [64-66]. Many hormones like auxin and cytokinin have been supposed to participate in cell cycle processes [67-69]. Moreover, the plant cell metabolism is closely associated with the cell wall loosening ability [70, 71]. According to the (Additional file 1: Table S12), Glyma04g05840 and Glyma19g37820 have five and one GO annotations, respectively. Glyma04g05840 contained a FAD domain and was noted the capability of binding both FAD and cytokinin substrates which participated in cytokinin metabolic process. Moreover, Glyma04g05840 was derived from a major interval of qLT4G-2 on chromosome 04 and was estimated relatively great expression in leaf tissues on Phytozome. Comparably, Glyma19g37820 was obtained from the interval of $q L T 19 Z-2$. This gene contained a LysM domain with evaluatively significant expression in shoot tip and GO annotation showed its participation in cell wall macromolecule catabolic process which may be important in cell wall loosen ability adjustment. Likewise, Glyma14g07140 and Glyma19g39340 were originated from the hereditary interval of Z-loci-37 and G-loci-94, respectively (Additional file 1: Table S13). Leaf width is influenced by the cell paraxial growth. In this study, Glyma14g07140 had a HAT1 domain that considered to connect with the cell cycle and was noted relatively great expression in shoot apical meristem (SAM). Furthermore, it was identified from leaf width loci (Z-loci-37) in ZH RIL population. This gene may be valuable in controlling the cell paraxial growth in soybean leaf and affect leaf width. Another putative gene Glyma19g39340 that encoded a B3 binding domain was an auxin response transcript factor gene, which was predicted to have a high expression in SAM as well. Taken together, we assumed these four genes as the candidate genes for soybean leaf type traits in this study. Nevertheless, these selected genes should be further probed in more prospective validations and comprehensively linked them to yield traits related genes to fully demonstrate their roles in soybean leaf development.

\section{Conclusions}

In this study, we fine mapped five soybean leaf type associated traits by using two recombinant inbred line (RIL) populations (Zhonghuang $24 \times$ Huaxia 3; Guizao $1 \times$ Brazil 13) and their constructed high-density genetic maps. A total of 190 QTLs for leaf type associated traits were detected. Among them, 103 QTLs were found to be correlated to the published ones for leaf type traits. Moreover, 14 stable loci for specific leaf type trait were identified and four major QTL hotspots for relevant leaf type traits were classified. Furthermore, four candidate genes originating from the hereditary intervals of the stable loci and the important QTL hotspots were predicted. The putative genes may directly or indirectly affect soybean leaf type and these intervals would be great value to improve valuable leaf type in future soybean breeding.

\section{Methods}

\section{Plant materials and field trials}

A GB RIL population with 256 RILs was obtained from a cross between 'Guizao 1' (ovule parent) and 'Brazil 13' (pollen parent) using a single seed descent (SSD) method derived from individual $F_{2}$ plants [72]. Guizao 1' is a cultivar from Cash Crops Research Institute, Guangxi Academy of Agricultural Sciences. 'Brazil 13' was introduced from a Brazilian germplasm variety named 'BRSMG 68'. Another ZH RIL population, which contains 164 RILs was also developed with SSD approach from 'Zhonghuang 24' (female parent) and 'Huaxia 3' (male parent). 'Zhonghuang 24' is a cultivar adaptive to Huang-Huai-Hai Rivers Valley China. 'Huaxia 3' is a high-yielding variety which, and was obtained from by South China Agriculture University. The $F_{13}$ GB RILs together with both parents were planted at the Zengcheng experimental station $\left(\mathrm{N} 23^{\circ} 24^{\prime}, \mathrm{E} 113^{\circ} 64^{\prime}\right)$ in the summer of 2016 for the pre-experiment; the $\mathrm{F}_{14}$ GB RILs were grown at the Zengcheng experimental station in the spring of 2017 and in the summer of 2017 both at the Zengcheng experimental station and the Guangzhou experimental station (N23 $\left.{ }^{\circ} 15^{\prime}, \mathrm{E} 113^{\circ} 34^{\prime}\right)$. The $F_{12}$ ZH RILs were grown together with both parents at the Zengcheng experimental station in the spring and summer of 2017. We adopted a randomized complete block planting with three replications. 
Each plot contained 10 plants per row, with $0.5 \mathrm{~m}$ between the rows and $0.1 \mathrm{~m}$ between the plants. Field management followed normal soybean production practices for the area.

\section{Measurement of leaf type traits and data analysis}

The testing targets were the five plants in the middle of each row. According to the former research carried out by Hanway and Thompson, we concentrated on four representative growth stages for leaf type associated traits scoring: the 6th node vegetative stage (V6), the full bloom reproductive growth stage (R2), the full pod reproductive growth stage (R4), and the full seed reproductive growth stage (R6) [73]. The material testing condition details are as listed below: ZH RIL population, the V6, R4 and R6 growth stages in the summer of 2017 at Zengcheng, the R2 growth stage in the spring of 2017 at Zengcheng; GB RIL population, the V6 growth stage in the summer of 2017 at Zengcheng, the R2 growth stage in the spring of 2017 at Zengcheng, the R4 growth stage in the summer of 2016 at Zengcheng, the R6 growth stage in the summer of 2017 at Zengcheng and Guangzhou two experimental stations.

We took the fully developed middle leaflets with petioles of the third node on the main stem counting down from the top. The leaf samples were collected and stored in a $4^{\circ} \mathrm{C}$ room and waited for the test [9]. By using an EPSON scanner, Picasa 3 (https://picasa.en. softonic.com/) and Image-Pro Plus 7.0 (http://www.mediacy.com/) software, we obtained the phenotypic values for LA, LL, LW and PL. The LS values were determined by the ratio LL to LW. Frequency distribution graphs were created by Graphpad prism 7.0 (http:// www.graphpad.com/). Statistical analysis was calculated by SPSS Statistics 19.0 (https://www.ibm.com/products/spss-statistics).

\section{Genetic map and QTL detection SNP genotyping}

Using a SOAP aligner (http://soap.genomics.org.cn/) software, the sequencing reads of the parents and each RILs were aligned to the soybean reference genome from Williams 82 [74]. The SOAP alignment results were formatted and then converted into input files using SAMtools (http://samtools.sourceforge.net/) [75]. The SNPs in RILs were identified by realSFS software. The likelihoods of genotypes for each individual were integrated and extracted as candidate SNPs and then filtering these SNPs by following criteria: $40 \leq$ depth $\leq$ 2500 , sites with a probability $\geq 95 \%$. Adopting the sliding window approach which contained 15 SNPs per window, to identify the genotype for each window and the exchange sites for each individual by sliding an SNP every time. Finally, the genotypes for each individual were applied for generating bin information [76]. All the genotyping work was conducted at the Beijing Genome Institute (BGI) Tech, Shenzhen, China.

\section{QTL detection}

Based on $0.2 \times$ RAD-seq and the bin genotypes of the RIL populations, two high-density genetic linkage maps were ultimately constructed by MSTMap (http://alumni.cs.ucr. edu/ yonghui/mstmap.html) and MapChart (https:// www.wur.nl/en/show/MapChart-2.32.htm) [77]. The composite interval mapping (CIM) method was employed to scan QTLs by WinQTLCart (http://statgen.ncsu.edu/ qtlcart/WQTLCart.htm) software [78, 79]. The LOD thresholds for QTL significance were evaluated by 1000 replications test with a genome-wide at the $5 \%$ level of significance to justify the existence of QTLs. According to the tests, a LOD score of 2.5 was used as a minimum to announce the presence of a QTL in a particular genomic region [80]. Running result of software can show additive effects of QTLs and phenotypic variation. QTL mapping results were comprehensively compared to SoybaseDatabase (https://www.soybase.org/).

\section{QTL naming}

According to Cui et al., all the QTLs were named as follows: initial ' $\mathrm{q}$ ' denotes 'QTL'; following with leaf type associated traits abbreviation letters; the next number is the soybean chromosomes on which the QTL is distributed [81]. Moreover, letters ' $a$ ' to 'd' represent the QTL was detected in ZH RIL population at the V6, R2, R4 and R6 growth stages at Zengcheng, respectively; letters ' $e$ ' to ' $i$ ' refer to the QTL for GB RIL population detected at the V6, R2, R4 and R6 growth stages at Zengcheng, respectively; letter ' $i$ ' means the QTL was discovered in GB RIL population at the R6 growth stage at the Guangzhou experimental station; if more than one QTL for a specific leaf trait was dispersed along a certain chromosome, a serial number, viz.-1, 2, etc., is used after the ' $a$ ' to ' $i$ ' to describe their order.

\section{Gene ontology (GO) enrichment analysis}

In this study, the Glyma.Wm82. a1. v1.1 gene model from SoyBaseDatabase was used for identification of the genes that fall into the genetic intervals of the detected QTLs. The AgriGo toolkit v2.0 (http://systemsbiology.cau.edu. cn/agriGOv2) was utilized to perform gene ontology (GO) analysis for these genes [82]. 


\section{Additional file}

Additional file 1: Table S1. The pairwise correlation coefficients between different leaf type traits in ZH RILs across multi-environments. Table S2. The pairwise correlation coefficients between different leaf type traits in GB RILs across multi-environments. Table S3. Correlation coefficients between different environments for leaf type traits in ZH RILs. Table S4. Correlation coefficients between different environments for leaf type traits in GB RILs. Table S5. Description of characteristics of 20 chromosomes in $\mathrm{ZH}$ RIL population high-density genetic map. Table S6. Description of characteristics of 20 chromosomes in GB RIL population high-density genetic map. Table S7. Fifty-six QTLs and 48 loci for leaf type traits in ZH RIL population across environments. Table S8. One hundred thirtyfour QTLs and 100 loci for leaf type traits in GB RIL population across environments. Table S9. Eleven QTL hotspots associated with leaf type traits detected in ZH RIL population. Table S10. Twenty-three QTL hotspots associated with leaf type traits detected in GB RIL population. Table S11. Gene models on Genome build Glyma 1.1 Chromosome of four important QTL hotspots. Table S12. Gene Ontology (GO) enrichment analysis of four important QTL hotspots. Table S13. Gene models on Genome build Glyma 1.1 Chromosome of specific leaf type traits. Table S14. Gene Ontology (GO) enrichment analysis of specific leaf type traits. Table S15. Information of SoybaseDatabse published leaf type traits associated QTLs. Table S16. Comparisons of the dected QTLS in ZH RIL population between present research and previous stuides. Table S17.Comparisons of the dected QTLs in GB RIL population between present research and previous stuides. Table S18. Four important QTL hotspots contain several published leaf type and yieldrelated traits QTLs. (XLS $428 \mathrm{~kb}$ )

\section{Abbreviations}

bp: Base pair; CIM: Composite interval mapping; cM: Centimorgan; CV.: cultivar; GO: Gene ontology; LA: Leaf area; LAl: Leaf area index; LL: Leaf length; LS: Leaf shape; LW: Leaf width; MAS: Molecular assisted selection; NGS: Next generation sequencing; PL: Petiole length; QTL: Quantitative trait locus; $\mathrm{R}^{2}$ : Phenotypic variance; RAD-seq: Restriction-site associated DNA sequencing; RIL: Recombinant inbred line; SAM: Shoot apical meristem; SNP: Single nucleotide polymorphism; SSD: Single seed descent

\section{Acknowledgements}

No applicable.

\section{Funding}

This work was supported by the Science and Technology Projects of Guangzhou (201804020015), the National Key R\&D Program of China (2017YFD0101500), the China Agriculture Research System (CARS-04-PS09) and the Research Project of the State Key Laboratory of Agricultural and Biological Resources Protection and Utilization in Subtropics (4100-M13024). The funding bodies had no role in study design, data collection, analysis and interpretation, decision to public, or writing of the manuscript

\section{Availability of data and materials}

The data sets supporting the results of this study are included in the manuscript. Soybean seeds are available from the Guangdong Subcenter of the National Center for Soybean Improvement, PR China.

\section{Authors' contributions}

HN took the lead for experimental design, supervised the research. LW participated in experimental design, conducted field experiments, phenotypic data collections, data analysis, candidate gene predictions and wrote the manuscript. YC developed the RIL populations. QM guided the experiments and revised the manuscript. YM provided the testing method of phenotypic data. ZH participated in phenotypic data collections and data analysis. QX and GZ was responsible for genotyping work and mapping the QTLs. All authors read and approved the final manuscript.

Ethics approval and consent to participate Not applicable.
Consent for publication

Not applicable.

\section{Competing interests}

The authors declare that they have no competing interests.

\section{Publisher's Note}

Springer Nature remains neutral with regard to jurisdictional claims in published maps and institutional affiliations.

\section{Author details}

${ }^{1}$ The State Key Laboratory for Conservation and Utilization of Subtropical Agro-bioresources South China Agricultural University, Guangzhou 510642, Guangdong, People's Republic of China. ${ }^{2}$ The Key Laboratory of Plant Molecular Breeding of Guangdong Province, College of Agriculture, South China Agricultural University, Guangzhou 510642, Guangdong, People's Republic of China. ${ }^{3}$ The Guangdong Subcenter of the National Center for Soybean Improvement, College of Agriculture, South China Agricultural University, Guangzhou 510642, Guangdong, People's Republic of China. ${ }^{4}$ Beijing Genomics Institute (BGI)-Shenzhen, Shenzhen 518086, People's Republic of China.

Received: 18 August 2018 Accepted: 14 March 2019

Published online: 02 April 2019

\section{References}

1. Du H, Yang SS, Liang Z, Feng BR, Liu L, Huang YB, Tang YX. Genome-wide analysis of the MYB transcription factor superfamily in soybean. BMC Plant Biol. 2012;12:106.

2. Z Zhang WK, Wang YJ, Luo GZ, Zhang JS, He CY, Wu XL, Gai JY, Chen SY. QTL mapping of ten agronomic traits on the soybean (Glycine max L. Merr.) genetic map and their association with EST markers. Theor Appl Genet. 2004;108:1131-9.

3. Heath OVS, Gregory FG. The constancy of the mean net assimilation rate and its ecological importance. Ann Bot. 1938;2:811-8.

4. Board JE, Harville BG. Explanations for greater light interception in narrowvs. wide-row. Crop Sci. 1992;32:198-202.

5. Baldocchi DD, Verma SB, Rosenberg NJ, Blad BL, Specht JE. Microclimateplant architectural interactions: influence of leaf width on the mass and energy exchange of a soybean canopy. Agric For Meteorol. 1985;35:1-20.

6. Johnson HW, Bernard RL. Soybean genetics and breeding. Adv Agron. 1962;14:149-221.

7. Jeong N, Moon JK, Kim HS, Kim CG, Jeong SC. Fine genetic mapping of the genomic region controlling leaflet shape and number of seeds per pod in the soybean. Theor Appl Genet. 2011;122:865-74.

8. Sayama T, Tanabata T, Saruta M, Yamada T, Anai T, Kaga A, Ishimoto M. Confirmation of the pleiotropic control of leaflet shape and number of seeds per pod by the Ln gene in induced soybean mutants. Breed Sci. 2017; 67:363-9.

9. Jun TH, Freewalt K, Michel AP, Mian R. Identification of novel QTL for leaf traits in soybean. Plant Breed. 2014;133:61-6.

10. Jun TH, Kang ST. Genetic map of Ips3: a new short petiole gene in soybeans. Genome. 2012;55:140-6.

11. Monir MM, Zhu J. Dominance and epistasis interactions revealed as important variants for leaf traits of maize NAM population. Front Plant Sci. 2018;9:627.

12. Tanksley SD, Ganal MW, Prince JP, Vicente MCD, Bonierbale MW, Broun P, Fulton TM, Giovannoni JJ, Grandillo S, Martin GB. High density molecular linkage maps of the tomato and potato genomes. Genetics. 1992;132: 1141-60.

13. Deokar AA, Ramsay L, Sharpe AG, Diapari M, Sindhu A, Bett K, Warkentin TD, Tar'an B. Genome wide SNP identification in chickpea for use in development of a high density genetic map and improvement of chickpea reference genome assembly. BMC Genomics. 2014;15:708.

14. Wang SS, Chen RK, Chen KY, Liu CY, Kao SM, Chung CL. Genetic mapping of the qSBN7 locus, a QTL controlling secondary branch number per panicle in rice. Breed Sci. 2017:67:340-7.

15. Pegadaraju V, Nipper R, Hulke B, Qi L, Schultz Q. De novo sequencing of sunflower genome for SNP discovery using RAD (restriction site associated DNA) approach. BMC Genomics. 2013;14:556. 
16. Pujol V, Forrest KL, Zhang P, Rouse MN, Hayden MJ, Huang L, Tabe L, Lagudah E. Identification of a stem rust resistance locus effective against Ug99 on wheat chromosome 7AL using a RAD-Seq approach. Theor Appl Genet. 2015;128:1397-405.

17. Wang N, Fang L, Xin H, Wang L, Li S. Construction of a high-density genetic map for grape using next generation restriction-site associated DNA sequencing. BMC Plant Biol. 2012;12:148.

18. Cai ZD, Cheng YB, Ma ZW, Liu XG, Ma QB, Xia QJ, Zhang GY, Mu YH, Nian $\mathrm{H}$. Fine-mapping of QTLs for individual and total isoflavone content in soybean (Glycine max L.) using a high-density genetic map. Theor Appl Genet. 2018;131:555-68.

19. Cheng YB, Ma QB, Ren HL, Xia QJ, Song EL, Tan ZY, Li SX, Zhang GY, Nian $\mathrm{H}$. Fine mapping of a Phytophthora-resistance gene RpsWY in soybean (Glycine max L.) by high-throughput genome-wide sequencing. Theor Appl Genet. 2017;130:1041-51.

20. Liu NX, Li M, Hu XB, Ma QB, Mu YH, Tan ZY, Xia QJ, Zhang GY, Nian H. Construction of high-density genetic map and QTL mapping of yieldrelated and two quality traits in soybean RILs population by RADsequencing. BMC Genomics. 2017;18:466.

21. Yue YL, Liu NX, Jiang BJ, Li M, Wang HJ, Jiang Z, Pan HT, Xia QJ, Ma QB, Han TF, Nian H. A single nucleotide deletion in J encoding GmELF3 confers long juvenility and is associated with adaption of tropic soybean. Mol Plant. 2017;10:656-8.

22. Dong H, Zhao H, Li S, Han Z, Hu G, Liu C, Yang G, Wang G, Xie W, Xing Y. Genome-wide association studies reveal that members of bHLH subfamily 16 share a conserved function in regulating flag leaf angle in rice (Oryza sativa). PLoS Genet. 2018;14:e1007323.

23. Li J, Tang W, Zhang YW, Chen KN, Wang C, Liu Y, Zhan Q, Wang C, Wang SB, Xie SQ, Wang L. Genome-wide association studies for five forage qualityrelated traits in sorghum (Sorghum bicolor L.). Front Plant Sci. 2018:9:1146.

24. Phan NT, Trinh LT, Rho MY, Park TS, Kim OR, Zhao J, Kim HM, Sim SC. Identification of loci associated with fruit traits using genome-wide single nucleotide polymorphisms in a core collection of tomato (Solanum lycopersicum L.). Sci Hortic. 2019;243:567-74.

25. Fang C, Ma YM, Wu SW, Liu Z, Wang Z, Yang R, Hu GH, Zhou ZK, Yu H, Zhang M, Pan Y, Zhou GA, Ren HX, Du WG, Yan HR, Wang YP, Han DZ, Shen YT, Liu SL, Liu TF, Zhang JX, Qin H, Yuan J, Yuan XH, Kong FJ, Liu BH, Li JY, Zhang ZW, Wang GD, Zhu BG, Tian ZX. Genome-wide association studies dissect the genetic networks underlying agronomical traits in soybean. Genome Biol. 2017;18:161.

26. Xavier A, Hall B, Casteel S, Muir W, Rainey KM. Using unsupervised learning techniques to assess interactions among complex traits in soybeans. Euphytica. 2017;213:200.

27. Tian ZX, Wang XB, Lee R, Li YH, Specht JE, Nelson RL, McClean PE, Qiu LJ, Ma JX. Artificial selection for determinate growth habit in soybean. Proc Natl Acad Sci U S A. 2010;107:8563-8.

28. Herrera-Foessel SA, Lagudah ES, Huerta-Espino J, Hayden MJ, Bariana HS, Singh D, Singh RP. (2011) new slow-rusting leaf rust and stripe rust resistance genes Lr67 and Yr46 in wheat are pleiotropic or closely linked. Theor Appl Genet. 2011;122:239-49.

29. Sonah H, O'Donoughue L, Cober E, Rajcan I, Belzile F. Identification of loci governing eight agronomic traits using a GBS-GWAS approach and validation by QTL mapping in soybean. Plant Biotechnol J. 2015;13:211-21.

30. Tan C, Han ZM, Yu HH, Zhan W, Xie WB, Chen X, Zhao H, Zhou FS, Xing YZ. QTL scanning for rice yield using a whole genome SNP array. J Genet Genomics. 2013:40:629-38.

31. Yamanaka N, Ninomiya S, Hoshi M, Tsubokura $Y$, Yano M, Nagamura $Y$, Sasaki T, Harada K. An informative linkage map of soybean reveals QTLs for flowering time, leaflet morphology and regions of segregation distortion. DNA Res. 2001:8:61-72.

32. Vieira AJD, Oliveira DAD, Soares TCB, Schuster I, Piovesan ND, Martínez CA Barros EG, Moreira MA. Use of the QTL approach to the study of soybean trait relationships in two populations of recombinant inbred lines at the $\mathrm{F}_{7}$ and $F_{8}$ generations. Braz J Plant Physiol. 2006;18:281-90.

33. Mian MAR, Ashley DA, Boerma HR. An additional QTL for water use efficiency in soybean. Crop Sci. 1998;38:390-3.

34. Orf JH, Chase K, Jarvik T, Mansur LM, Cregan PB, Adler FR, Lark KG. Genetics of soybean agronomic traits: I Comparison of three related recombinant inbred populations. Crop Sci. 1999;39:1642-51.

35. Mansur LM, Orf JH, Chase K, Jarvik T, Cregan PB, Lark KG. Genetic mapping of agronomic traits using recombinant inbred lines of soybean. Crop Sci. 1996;36:1327-36.
36. Mansur LM, Lark KG, Kross H, Oliveira A. Interval mapping of quantitative trait loci for reproductive, morphological, and seed traits of soybean (Glycine max L.). Theor Appl Genet. 1993;86:907-13.

37. Keim P, Diers BW, Olson TC, Shoemaker RC. RFLP mapping in soybean: association between marker loci and variation in quantitative traits. Genetics. 1990;126:735-42.

38. Kim HK, Kang ST, Suh DY. Analysis of quantitative trait loci associated with leaflet types in two recombinant inbred lines of soybean. Plant Breed. 2005;124:582-9.

39. Chen QS, Zhang ZC, Liu CY, Xin DW, Qiu HM, Shan DP, Shan CY, Hu GH. QTL analysis of major agronomic traits in soybean. Agric Sci China. 2007;6: 399-405.

40. Shim HC, Ha BK, Yoo M, Kang ST. Detection of quantitative trait loci controlling UV-B resistance in soybean. Euphytica. 2015;202:109-18.

41. Lee JS, Kim S, Ha BK, Kang S. Positional mapping and identification of novel quantitative trait locus responsible for UV-B radiation tolerance in soybean [Glycine max (L.) Merr.]. Mol Breeding. 2016;36:50.

42. Yao D, Liu ZZ, Zhang J, Liu SY, Qu J, Guan SY, Pan LD, Wang D, Liu JW, Wang PW. Analysis of quantitative trait loci for main plant traits in soybean. Genet Mol Res. 2015;14:6101-9.

43. Lee $\mathrm{S}$, Jun TH, Michel AP. Mian MAR. SNP markers linked to QTL conditioning plant height, lodging, and maturity in soybean. Euphytica. 2015:203:521-32.

44. Li D, Sun M, Han Y, Teng W, Li W. Identification of QTL underlying soluble pigment content in soybean stems related to resistance to soybean white mold (Sclerotinia sclerotiorum). Euphytica. 2010;172:49-57.

45. Kim KS, Diers BW, Hyten DL, Rouf Mian MA, Shannon JG, Nelson RL. Identification of positive yield QTL alleles from exotic soybean germplasm in two backcross populations. Theor Appl Genet. 2012;125: 1353-69.

46. Lee SH, Bailey MA, Mian MAR, Carter TE, Ashley DA, Hussey RS, Parrott WA, Boerma HR. Molecular markers associated with soybean plant height, lodging, and maturity across locations. Crop Sci. 1996;36:728-35.

47. Palomeque L, Li-Jun L, Li W, Hedges B, Cober ER, Rajcan I. QTL in megaenvironments: I. Universal and specific seed yield QTL detected in a population derived from a cross of high-yielding adaptedxhigh-yielding exotic soybean lines. Theor Appl Genet. 2009;119:417-27.

48. Sayama T, Hwang TY, Yamazaki H, Yamaguchi N, Komatsu K, Takahashi M, Suzuki C, Miyoshi T, Tanaka Y, Xia Z, Tsubokura Y, Watanabe S, Harada K, Funatsuki $H$, Ishimoto M. Mapping and comparison of quantitative trait loci for soybean branching phenotype in two locations. Breed Sci. 2010;60:380-9.

49. Vuong TD, Sonah H, Meinhardt CG, Deshmukh R, Kadam S, Nelson RL, Shannon JG, Nguyen HT. Genetic architecture of cyst nematode resistance revealed by genome-wide association study in soybean. BMC Genomics. 2015;16:593.

50. Lee SH, Bailey MA, Mian MAR, Shipe ER, Ashley DA, Parrott WA, Hussey RS, Boerma HR. Identification of quantitative trait loci for plant height, lodging, and maturity in a soybean population segregating for growth habit. Theor Appl Genet. 1996;92:516-23.

51. Zhang J, Song Q, Cregan PB, Nelson RL, Wang X, Wu J, Jiang GL. Genomewide association study for flowering time, maturity dates and plant height in early maturing soybean (Glycine max) germplasm. BMC Genomics. 2015; 16:217.

52. Contreras-Soto RI, Mora F, de Oliveira MA, Higashi W, Scapim CA, Schuster I. A genome-wide association study for agronomic traits in soybean using SNP markers and SNP-based haplotype analysis. PLoS One. 2017;12: e0171105.

53. Yang Z, Xin D, Liu C, Jiang H, Han X, Sun Y, Qi Z, Hu G, Chen Q. Identification of QTLs for seed and pod traits in soybean and analysis for additive effects and epistatic effects of QTLs among multiple environments. Mol Gen Genomics. 2013;288:651-67.

54. Zhang D, Cheng H, Wang H, Zhang H, Liu C, Yu D. Identification of genomic regions determining flower and pod numbers development in soybean (Glycine max L.). J Genet Genomics. 2010;37:545-56.

55. Kuroda Y, Kaga A, Tomooka N, Yano H, Takada Y, Kato S, Vaughan D. QTL affecting fitness of hybrids between wild and cultivated soybeans in experimental fields. Ecol Evol. 2013:3:2150-68.

56. Funatsuki H, Kawaguchi K, Matsuba S, Sato Y, Ishimoto M. Mapping of QTL associated with chilling tolerance during reproductive growth in soybean. Theor Appl Genet. 2005;111:851-61. 
57. Ning H, Yuan J, Dong Q, Li W, Xue H, Wang Y, Tian Y, Li WX. Identification of QTLS related to the vertical distribution and seed-set of pod number in soybean [Glycine max (L.) Merri]. PLoS One. 2018;13:e0195830.

58. Csanádi G, Vollmann J, Stift G, Lelley T. Seed quality QTLs identified in a molecular map of early maturing soybean. Theor Appl Genet. 2001;103:912-9.

59. Hoeck JA, Fehr WR, Shoemaker RC, Welke GA, Johnson SL, Cianzio SR. Molecular marker analysis of seed size in soybean. Crop Sci. 2003;43:68-74.

60. Wang J, Chen P, Wang D, Shannon G, Shi A, Zeng A, Orazaly M. Identification of quantitative trait loci for oil content in soybean seed. Crop Sci. 2015;55:23-34.

61. Hu Z, Zhang D, Zhang G, Kan G, Hong D, Yu D. Association mapping of yieldrelated traits and SSR markers in wild soybean (Glycine soja Sieb. And Zucc.). Breed Sci. 2014;63:441-9.

62. Du W, Wang M, Fu S, Yu D. Mapping QTLs for seed yield and drought susceptibility index in soybean (Glycine max L.) across different environments. J Genet Genomics. 2009:36:721-31.

63. Ichihashi Y, Tsukaya H. Behavior of leaf meristems and their modification. Front Plant Sci. 2015;6:1060.

64. Sluis A, Hake S. Organogenesis in plants: initiation and elaboration of leaves. Trends Genet. 2015;31:300-6.

65. Szymanski DB. The kinematics and mechanics of leaf expansion: new pieces to the Arabidopsis puzzle. Curr Opin Plant Biol. 2014;22:141-8.

66. Zhang JZ, Wei BY, Yuan RR, Wang JH, Ding MX, Chen ZY, Yu H, Qin GJ. The Arabidopsis RING-type E3 ligase TEAR1 controls leaf development by targeting the TIE1 transcriptional repressor for degradation. Plant Cell. 2017; 29:243-59.

67. Guan CM, Wu BB, Yu T, Wang QQ, Krogan NT, Liu XG, Jiao YL. Spatial auxin signaling controls leaf flattening in Arabidopsis. Curr Biol. 2017;27:2940-50.

68. Haq BU, Ahmad MZ, Ur Rehman N, Wang JJ, Li PH, Li DQ, Zhao J.

Functional characterization of soybean strigolactone biosynthesis and signaling genes in Arabidopsis MAX mutants and GmMAX3 in soybean nodulation. BMC Plant Biol. 2017;17:259.

69. Mohammed B, Bilooei SF, Dóczi R, Grove E, Railo S, Palme K, Ditengou FA, Bögre L, López-Juez E. Converging light, energy and hormonal signaling control meristem activity, leaf initiation, and growth. Plant Physiol. 2018;176: 1365-81.

70. Kierzkowski D, Nakayama N, Routier-Kierzkowska AL, Weber A, Bayer E, Schorderet M, Reinhardt D, Kuhlemeier C, Smith RS. Elastic domains regulate growth and organogenesis in the plant shoot apical meristem. Science. 2012;335:1096-9.

71. Marowa P, Ding AM, Kong YZ. Expansins: roles in plant growth and potential applications in crop improvement. Plant Cell Rep. 2016;35:949-65.

72. Funada M, Helms TC, Hammond JJ, Hossain K, Doetkott C. Single-seed descent, single-pod, and bulk sampling methods for soybean. Euphytica. 2013:192:217-26

73. Hanway JJ, Thompson HE. How a soybean plant develops. 1962. Available from https://lib.dr.iastate.edu/specialreports/62.

74. Li RQ, Li YR, Kristiansen K, Wang J. SOAP: short oligonucleotide alignment program. Bioinformatics. 2008;24:713-4.

75. Li H, Handsaker B, Wysoker A, Fennell T, Ruan J, Homer N, Marth G, Abecasis G, Durbin R. The sequence alignment/map (SAM) format and SAM tools. Bioinformatics. 2009;25:2078-9.

76. Huang XH, Feng Q, Qian Q, Zhao Q, Wang L, Wang AH, Guan JP, Fan DL, Weng QJ, Huang T, Dong GJ, Sang T, Han B. High-throughput genotyping by whole-genome resequencing. Genome Res. 2009;19:1068-76.

77. Voorrips RE. MapChart: software for the graphical presentation of linkage maps and QTLS. J Hered. 2002;93:77-8.

78. Han YP, Teng WL, Yu KF, Poysa V, Anderson T, Qiu LJ, Lightfoot DA, Li WB. Mapping QTL tolerance to Phytophthora root rot in soybean using microsatellite and RAPD/SCAR derived markers. Euphytica. 2008:162:231-9.

79. Li HH, Ye GY, Wang JK. A modified algorithm for the improvement of composite interval mapping. Genetics. 2007:175:361-74.

80. Zeng ZB. Theoretical basis for separation of multiple linked gene effects in mapping quantitative trait loci. Proc Natl Acad Sci U S A. 1993;90:10972-6.

81. Cui F, Zhao CH, Ding AM, Li J, Wang L, Li XF, Bao YG, Li JM, Wang HG. Construction of an integrative linkage map and QTL mapping of grain yield-related traits using three related wheat RIL populations. Theor Appl Genet. 2014;127:659-75.

82. Tian T, Liu Y, Yan HY, You Q, Yi X, Du Z, Xu WY, Su Z. agriGO v2.0: a GO analysis toolkit for the agricultural community, 2017 update. Nucleic Acids Res. 2017:45:W122-9.

Ready to submit your research? Choose BMC and benefit from:

- fast, convenient online submission

- thorough peer review by experienced researchers in your field

- rapid publication on acceptance

- support for research data, including large and complex data types

- gold Open Access which fosters wider collaboration and increased citations

- maximum visibility for your research: over $100 \mathrm{M}$ website views per year

At $\mathrm{BMC}$, research is always in progress.

Learn more biomedcentral.com/submissions 